\title{
O que fazem (e como se fazem) os líderes escolares?
} Karina Carrasqueira

GOIS, Antônio. Líderes na escola: o que fazem bons diretores e diretoras, e como os melhores sistemas educacionais do mundo os selecionam, formam e apoiam. São Paulo: Moderna, 2020.

Antônio Gois não é, stricto sensu, um pesquisador acadêmico. É um jornalista, com mais de 20 anos de experiência cobrindo temas de educação. Contudo, em seu livro, como bem coloca André Lázaro, que assina o prefácio, Gois faz um excelente trabalho de "jornalismo científico". O livro não é apenas o relato de histórias, mas o resultado de uma pesquisa profunda de cerca de dois anos e meio, na qual realizou extenso levantamento bibliográfico, visitou escolas em países diferentes, entrevistou gestores públicos, diretores, professores, pais de alunos e pesquisadores, e ainda aplicou questionários às secretarias estaduais de educação do país.

O livro conta histórias reais de diretoras e diretores que, por meio de sua liderança, conseguiram fazer de suas escolas - muitas delas em regiões marginalizadas e que enfrentavam muitas dificuldades - exemplos de sucesso e superação.

Embora tenha um posicionamento otimista, em nenhum momento, o autor é ingênuo. Completamente ancorado no que há de mais atual e relevante na literatura nacional e internacional sobre gestão escolar, Gois deixa claro que os problemas educacionais são multidimensionais e que a escola sozinha não é capaz de resolver os problemas da estrutura social.

O fato de ter sido escrito por um jornalista torna a leitura mais leve e fluida, mas, de forma alguma mais rasa. As personagens que nos vão sendo apresentadas a cada capítulo ilustram e personificam teorias abstratas contidas em artigos e livros científicos. É um tipo de narrativa que aproxima o leitor. E isso é especialmente importante para apresentar resultados acadêmicos a um público menos inserido na - geralmente dura e pragmática - escrita acadêmica.

No livro, conhecemos realidades distintas que se entrecruzam nas figuras de cinco diretoras e um diretor de escolas no Brasil, México, Chile, Estados 
Unidos, Canadá e Singapura. O que o autor nos mostra é que gestores que se tornam líderes escolares eficazes apresentam práticas semelhantes, que podem ser completamente intuitivas - como no Brasil - ou desenvolvidas como parte de uma política pública altamente estruturada que começa desde a formação inicial - como em Singapura. O principal argumento do autor é que quanto mais estruturado e colaborativo o processo, quanto mais apoio professores e diretores receberem continuamente desde o seu primeiro dia na profissão, maiores as chances de o sistema como um todo melhorar de forma sustentável.

\section{De Luziápolis a Singapura}

O livro é dividido em duas partes. A primeira, que tem 10 capítulos, começa nos apresentando Valquíria de Assis, uma diretora escolar no distrito de Luziápolis, em Campo Alegre, na Zona da Mata alagoana. Enquanto narra a trajetória dessa mulher que transformou duas escolas, que sofriam com vandalismo e indisciplina, em exemplos de sucesso, Gois vai fazendo interlocuções entre as práticas de Valquíria e as evidências trazidas por pesquisadores. Essa diretora enfrentou a resistência de professores e alunos, às vezes de forma dura, mas, principalmente, construindo relacionamentos de confiança e responsabilidade entre os membros da comunidade escolar.

No segundo capítulo dessa primeira parte, o autor aprofunda mais os aspectos teóricos, utilizando a experiência de Valquíria como exemplo. Há uma linha de pesquisa em desenvolvimento, que busca identificar práticas de diretores que têm impacto no desempenho escolar dos alunos. Ainda que se encontrem impactos diretos, entende-se que as ações da gestão vão influenciar várias dimensões escolares que, juntas, vão favorecer a aprendizagem.

No terceiro capítulo, nos é apresentada Irene Villafuerte, diretora de uma escola localizada em região de alta vulnerabilidade social do México. A história e as dificuldades de Irene se assemelham às de Valquíria. E começamos a ver o argumento do autor - baseado em evidências científicas - a respeito das características e das práticas de bons líderes.

A partir da história de Irene, no capítulo quatro, o autor discorre sobre 0 que as pesquisas em liderança da gestão indicam como principais características de diretoras e diretores eficazes. Embora deixe claro que não há uma receita, pois cada contexto escolar tem suas próprias especificidades e 
cada gestor ou gestora sabe o que priorizar em cada momento - o que já é em si uma característica desses líderes de sucesso -, há similaridades que são encontradas nas pesquisas.

Tanto Valquíria quanto Irene apresentam todas as características listadas -perseverança, coerência das ações, foco nos resultados, motivação e boa comunicação - e praticam ações-chave para o desenvolvimento da aprendizagem - escuta ativa de todos os atores escolares, distribuição da liderança, criação de uma cultura focada no pedagógico e o estabelecimento de um ambiente escolar organizado. Contudo, Irene e Valquíria realizaram o trabalho de forma intuitiva.

No capítulo cinco, conhecemos Marcela Villavicencio, diretora de uma escola no Chile que, assim como as das personagens anteriores, estava desacreditada. Quando chegou à instituição, ela teve de enfrentar problemas de indisciplina e infraestrutura precária. O perfil de trabalho de Marcela e sua história na escola são muito semelhantes aos de Valquíria e Irene, com a grande diferença de que Marcela passou por formações especializadas, alinhadas com uma política nacional e que a instrumentalizaram para realizar seu trabalho.

No Chile, as políticas voltadas à gestão têm como norteador o Marco para Boas Direção e Liderança Escolar. No capítulo seis, então, compreende-se melhor o contexto chileno, o como e o porquê desse documento ter sido desenvolvido. O marco se ancora em experiências e pesquisas internacionais, mas foi elaborado a partir de debates que contaram com a presença de professores, diretores escolares, pesquisadores e formuladores de políticas. $O$ documento apresenta práticas, princípios, habilidades e conhecimentos necessários para ser candidato a diretor/a escolar naquele país. Desse modo, orienta os cursos de formação e os concursos de seleção. Mais do que isso, orienta os gestores e as gestoras em seu trabalho nas escolas.

Depois do Chile, Gois nos leva a Nova York, no capítulo sete, para conhecer Noah Angeles, diretor de uma escola do Queens, região de maioria negra e latina. Diferente das outras diretoras apresentadas, Noah não precisou realizar grandes mudanças na escola que estava gerindo, o que ele fazia era garantir que as melhorias fossem sustentáveis.

O primeiro ponto importante que nos traz a experiência de Noah é que estágios diferentes exigem ações diferentes. Enquanto as primeiras diretoras 
precisavam se manter sempre disponíveis para a comunidade como forma de ganhar a confiança e o respeito, Noah buscava descentralizar a liderança para garantir que a escola funcionaria bem sem ele, ou seja, que não seria uma mudança personalista, mas de cultura.

O segundo ponto, que culmina no capítulo oito, são os programas de formação de diretores dos EUA. O capítulo discute os erros e acertos da política de Nova York no âmbito da NYC Leardership Academy e os da iniciativa da Wallace Foundation, que financiou a implementação de um modelo de formação de gestores em algumas redes educacionais do país.

Saindo dos EUA, é a vez de conhecer Michelle Lawrence, no capítulo nove, diretora de uma escola que recebe muitas crianças de famílias estrangeiras no Canadá. As práticas de Michelle são bem parecidas com as das diretoras apresentadas anteriormente. A diferença agora é efetivamente no sistema de Ontário, que busca identificar potenciais líderes entre seus profissionais e os direciona para processos formativos adequados.

O caso de Ontário mostra a importância de políticas públicas de suporte para gestores e professores. A formação e o apoio não terminam depois que eles estão em suas escolas: o sistema visa a criar uma cultura de colaboração que perdure. Eles entenderam que não basta cobrar por melhores desempenhos, é importante instrumentalizar os profissionais da educação e garantir o apoio necessário para que as mudanças no ambiente escolar ocorram.

Se o sistema educacional de Ontário já parece altamente estruturado e focado na formação de líderes, nada se compara com o de Singapura, exemplo apresentado no décimo e último capítulo da primeira parte do livro.

A formação de líderes em Singapura se dá desde o primeiro dia de trabalho e faz parte de um sistema de progressão de carreira, em que, ao subir, o profissional assume maior responsabilidade em apoiar e colaborar com os colegas. Além da formação continuada constante, os momentos de troca e colaboração entre as equipes ocupam a maior parte da carga horária de professores e diretores. O que faz de Singapura o melhor sistema educacional do mundo é o investimento nos seus profissionais.

\section{Do indivíduo ao sistema}


$\mathrm{Na}$ segunda parte do livro, o autor busca sistematizar o que foi apresentado na primeira parte. Em primeiro lugar, reforça a ideia de que não há um modelo único de líder - as personagens apresentadas tinham experiências de vida e personalidades muito diferentes. Também não há uma receita com passo a passo igual para todas as escolas, mesmo que certas práticas sejam observadas em todos as diretoras e diretores do livro.

Assim, no décimo primeiro capítulo, Gois descreve práticas eficazes construir objetivos comuns, desenvolver pessoas, estreitar laços com a comunidade, criar um bom clima escolar, estabelecer relações de confiança, foco no trabalho pedagógico - encontradas na literatura e observadas nas personagens do livro. O que é apontado pelo autor e reforçado pelas pesquisas é que uma gestão eficaz é aquela com foco no aluno, capacidade de escuta, inconformismo, distribuição da liderança. No entanto, cada situação exige ações específicas, e cada diretor/a tem de entender como agir para atacar os problemas, inclusive identificando qual atacar primeiro.

Entretanto, apenas "boa vontade", iniciativa e liderança do diretor podem não ser suficientes, se o sistema educacional não colaborar, como nos mostra no capítulo doze. A falta de diretrizes e as inconsistências na legislação podem inviabilizar o trabalho ativo dos diretores escolares, fazendo com que eles sejam apenas gestores das finanças da escola. Não é uma questão de minimizar a importância de administrar um órgão público que recebe dinheiro dos contribuintes. Porém, se a direção é sobrecarregada por trabalho burocrático, é provável que sobre pouco ou nenhum tempo para construir relações e desenvolver o trabalho pedagógico. O Brasil, como aponta o autor, está muito atrasado em termos de definição de matrizes para formação e seleção de lideranças.

A seleção é outro problema enfrentado pelas redes públicas brasileiras. Não há, como aponta o autor no capítulo treze, uma forma de seleção melhor, há a mais adequada para os propósitos do sistema. Pouco adianta ter uma eleição democrática, se a escolhida for alguém que não tenha características e/ou conhecimentos para liderar. Por outro lado, impor alguém na escola por meio de indicação ou seleção pode ter péssimos resultados, sobretudo se a pessoa não tiver o perfil indicado para aquela escola. É, portanto, importante 
aliar formação e perfil de liderança com as necessidades de cada escola. E apenas um sistema organizado consegue implementar esse tipo de ação.

A principal conclusão a que Gois nos faz chegar é que um sistema educacional não pode deixar a melhoria de suas escolas apenas na mão de diretores. É preciso toda uma rede de formação, apoio e colaboração constantes, para que as mudanças não sejam golpes de sorte, mas uma política pública consistente. 